\title{
PENGURANGAN PENGARUH NEGATIF GADGET PADA REMAJA DAN ANAK MELALUI WORKSHOP
}

\author{
${ }^{1}$ Nanndo Yannuansa, ${ }^{2}$ Humaidillah Kurniadi W, ${ }^{3}$ Akmam Mutrofin, ${ }^{4}$ Rahma Ramadhani, \\ ${ }^{5}$ Agung Samudra \\ ${ }^{1,2}$ Teknik Elektro, ${ }^{3,4}$ Teknik Sipil, ${ }^{5}$ Teknik Mesin, Universitas Hasyim Asy’ari Tebuireng Jombang \\ 1nanndoyannuansa@unhasy.ac.id/n4nnd0yan@gmail.com
}

\begin{abstract}
The development of technology today will certainly bring many changes to human life and nature. These changes must be addressed carefully to be able to bring positive influence. One off technology that develops is gadgets. It seems like gadgets can have such a big impact on cultural values. Gadgets are almost certainly owned by everyone. All good people certainly will not be separated from gadgets today's. So that the use of gadgets becomes a habit and even culture in a society today. Nevertheless as parents must be able to anticipate things/ mainstreaming the use of gadgets. This not only has a positive effect but also has a negative impact on children who have been introduced to gatged early on. One form of cooperation that will be carried out with Tanjung Wadung Village is a workshop on "Reducing the Negative Effects of Gadgets on Adolescents and Children". These results are expected to add insight into the positive and negative use of gatged. And able to reduce the negative impact on adolescents and children.
\end{abstract}

Keywords: Gatged, Youth, training

\begin{abstract}
Abstrak
Semakin berkembangnya teknologi pada dewasa ini tentunya akan banyak membawa perubahan pada kehidupan manusia dan alam. Perubahan-perubahan itu harus disikapi secara matang agar mampu membawa pengaruh positif. Teknologi yang berkembang salah satunya dalah gadget. Sepertinya gadget dapat memberikan dampak yang begitu besar pada nilai-nilai kebudayaan. Gadget dipastikan hamper dipunyai pada setiap orang. Semua kalangan baik dipastikan tidak akan terlepas dari gadget dewasa ini. Sehingga penggunaan gadget menjadi kebiasaan bahkan kebudayaan dalam suatu masyarakat sekarang ini. Meskipun demikian sebagai orang tua harus bias mengantisipasi hal-hal/ pengarush penggunaan gadget. Hal tersebut tidak hanya mendatangkan pengaruh postif saja tetapi juga mempunya dampak negative terutapa terhadap anak-anak yang sudah sejak dini dikenalkan kepada gatged. Salah satu bentuk kerja sama yang akan dilakukan dengan Desa Tanjung Wadung adalah workshop "Pengurangan Pengaruh Negatif Gadget Pada Remaja Dan Anak". Hasil ini diharapkan dapat menambah wawasan tentang postif dan negatifnya penggunaan gatged. Serta mampu mengurangi dampak negatifnya kepada remaja dan anak-anak.
\end{abstract}

Kata Kunci : Gatged, Remaja, pelatihan

\section{PENDAHULUAN}

Sukarno pernah berkata "Beri aku 1.000 orang tua, niscaya akan kucabut semeru dari akarnya. Beri aku 10 pemuda niscaya akan kuguncangkan dunia". Dari sini dapat diketahui pentingnya pemuda bagi kemajuan suatu bangsa. Karena nantinya pemuda yang akan menggantikan sebagai pemimpin generasi sesudahnya. Salah satu faktor yang perlu dipunyai oleh seorang pemimpin adalah ia mampu memimpin dirinya. Pendidikan karakter merupakan hal yang sangat penting sehingga perlu ditanamkan sejak dini.
Keluarga merupakan faktor penting dalam menanamkan pendidikan karakter sehingga kedepannya mampu bermasyarakat dengan baik. Akan tetapi menjadi tantangan baru dalam menanamkan pendidikan karakter karena perkembangan media dan tekhnologi yang sangat pesat. Banyak anak yang sejak usia dini diberikan keleluasaan dalam menggunakan gadget oleh orang tuanya dewasa ini. Para orang tua beralasan, penggunaan gadget oleh anak-anak lebih memudahkan dalam pengawasan dan lebih aman daripada beraktifitas diluar. Tetapi 
pengaruh-pengaruh dari penggunaan gadget belum terpikirkan oleh mereka

Pesatnya perubahan teknologi dewasa ini tentunya akan mempengaruhi pola kehiduapan manusia dalam berbagai bidang. Teknologi yang mempengaruhi manusia dalam nilai-nilai kebudayaan salah satunya adalah gadget. Gadget dapat dipastikan dimiliki oleh seluruh lapisan masyarakat. Tidak hanya kalangan dewasa saja, akan tetapi anak dan balita sudah mampu dan bisa menggunakan gadget dalam aktifitas kesehariaannya. Gadget banyak digunakan oleh setiap orang baik untuk kegiatan-kegiatan penting sampai sekedar menghabiskan waktu luang dalam hariharinya. Tentu saja hal tersebut membawa dampak bagi penggunanya. Manfaat positif dari gadget adalah Mempermudah Komunikasi. Membangun kreatifitas anak (Hadiwidjodjo, Psi 2014). Disamping itu Nilai positifnya yang lain mempermudah komunikasi, menambah pengetahuan, menambah teman. Akan tetapi banyak dampak negatif yang muncul antara lain merusak mata, nengbah postur tubuh, kulit wajah kendur, mengganggu pendengaran,menganggu saat istirahat (Puji Asmaul Chusna :2017) bahkan salah satu hasil penelitian yang dilakukan oleh Nurmalasari dan Devi Wulandari(2018) menyimpulkan ada pengaruh antara penggunaan gadget dengan konsentrasi siswa. Hal tersebut tentunya juga berdampak pada pretasi siswa. Senada dengan hasil penelitian dari Ramdhan dkk(2018) dimana adanya dampat negatife dari penggunaan gadget dalam interaksi sosial pada siswa SD.

Oleh karena itu sebagai yang sedikit lebih mengerti tentang bagaimana cara memanfaatkan teknlogi dengan baik dan benar, kami berinisiatif mengadakan workshop "Penanggulangan Pengaruh Gatged Pada Remaja Dan Anak-Anak".

Berdasarkan survey yang telah dilakukan di desa tanjung wadung kecamatan kabuh kabupaten jombang dengan permasalahan yang telah diidentifikasi, maka solusi yang ditawarkan PKM ini adalah mengadakan workshop “ Penanggulangan Pengaruh Gadget Pada Remaja Dan AnakAnak" dan demonstrasi terhadap cara mengenetahui situs-situs yang berbahaya serta cara mengatasinya tujuan dilakukan kegiatan ini agar remaja atau khususnya orang tua yang sudah memiliki buah hati untuk tau dampak dan pengaruh gadget agar lebih bijak menggunakannya. Dari materi yang sudah di bentuk kami bermaksut menanamkan agar bagaimana caranya manusia tidak di manfaatkan oleh Gadget tetapi manusia yang memanfaatkan gadget.

\section{METODE}

Pada prakteknya Pengabdian Pada Masyarakat ini dilakukan dengan menggunakan metode ceramah, diskusi, dan demonstrasi penanggulangan gatged

Berikut Langkah-langkah yang dilakukan untuk melaksanakan kegiatan pengabdian masyarakat Kegiatan pengabdian ini dilakukan di desa Tanjung wadung. dapat dilihat pada skema kegiatan pada Gambar

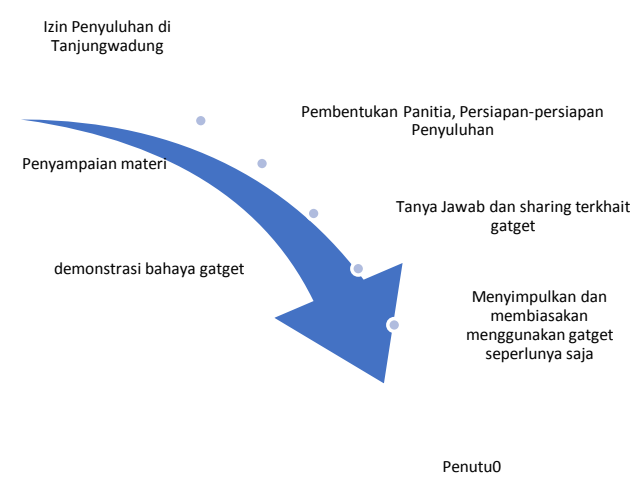
Gambar 1. Skema Langkah-langkah Kegiatan PPM

\section{HASIL DAN PEMBAHASAN}

Materi yang diberikan meliputi: 


\section{Pengetahuan gatget.}

Segala lapisan masyarakat baik dari segala bidang, usia dan tingkat pendidikan sudah mengunakan Gadget hal tersebut dampak dari perkembangan teknologi yang begitu pesat (Syahra :2006). Dalam bhasa inggris gadget diartikan perangkat elektronik yang mempunyai fungsi khusus. Akan tetapi ada perbedaan antara gadget dengan peragkat elektronik lainnya. Dan unsur "pembaharuan" merupakan perbedaan yang paling terlihat. Dengan kata lain gadget merukapan alat elektronik yang mengalami pembaharuan dari hari kehari guna semakin memudahkan kehidupan manusia. Dengan kata lain gadget membuat kehidupan manusia menjadi semakin praktis dan simple.

\section{Dampak Positif dan Negatif dalam Menggunakan Gadget}

Gadget sudah tidak asing lagi bagi semua kalangan baik dari dewasa sampai anak-anak. Para orang tua khususnya tidak begitu memikirkan dampak dari penggunaan gadget pada anak-anaknya. Padahal gadget dapat dimisalkan seperti uang logam mempunyai dampak positif dan negative.

Dapak positif pengguanaan gadget yaitu:

a. Urusan bisnis semakin mudah

b. Tugas-tugas yang berhubungan dengan iptek dapat diseleseikan dengan mudah dan cepat

c. Akses informasi semakin mudah didapat

d. E-mail dapat diakses secara mudah dengan genggaman gadget

e. Chating dengan saudara jauh sangat mudah

f. Perkembangan zaman dapat diikuti Dampak negatif Penggunakan gadget yaitu

a. Kesehatan tubuh dapat teganggu misal kerusakan mata akibat terlalu lama memandang layat gadget

b. Waktu yang terbuang sia-sia karena kecanduan game gadget c. Fisik yang mengalami kerusakan misalnya terkenanya lordosis dll, akibat punggung yang sering membungkuk.

d. Hilangnya waktu olah raga dan waktu berkumpul dengan keluarga

\section{Cara Bijak Menggunakan GADGET}

Sedangkan penggunaan gadget memerlukan cara tersediri agar gadget memberi pengaruh positif terhadap pemakainya. Berikut cara bijak menggunakan gadget

a. Batasi sendiri penggunaanya

b. Patuhi tata cara penggunaan alat elektronik.

c. Jangan main gadget sebelum tidur.

d. Menggunakan gadget sebagai media pembelajaran dan komunikasi.

e. Menghasilakan uang melalui gadget.

Sedangkan upaya menangani kecanduan gatget pada anak-anak.

a. Memperbanyak sosialisai dengan teman dan orang-orang terdekat.

b. Menghapus beberapa aplikasi yang membuat kamu kecanduan.

c. Luangkan waktu untuk hobi anda yang tidak menggunakan smartphone.

d. Menyimpan gadget di dalam tas saat sedang bepergian.

\section{Memberikan contoh/demonstrasi bahaya gatget dengan cara memblokir kontens dewasa pada YouTube dan Google}

\section{Pada Youtube}

Langkah awal orang tua dapat membuat "Restricted Mode/mode tebatas" dimana pada fitur tersebut ketika orang tua menginginkan kontrol hal-hal berbau porno dan berbahaya pada YouTube.

Caranya, buka aplikasi YouTube pada halaman bagian yang paling bawah selanjutnya klik [Restricted Mode: Off] dan selanjutnya akan ada pilihan dalam mengaktikan ON-OFF pada 
Restricted Mode seperti gambar berikut ini. Pilih tombol [On] jika menginginkan aktif dan pilih [Save].

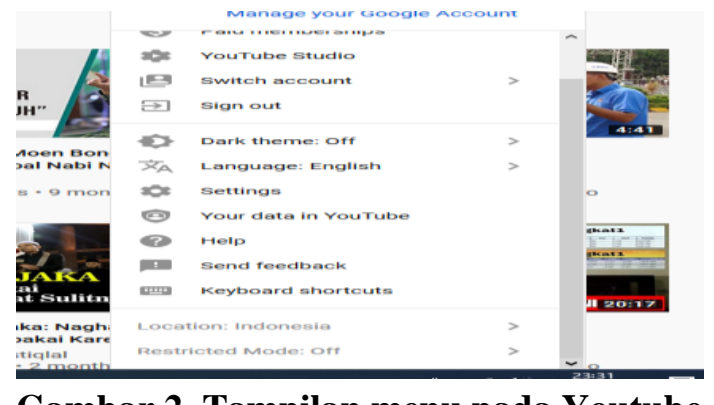

\section{Gambar 2. Tampilan menu pada Youtube}

Restricted mode yang awalnya "Off" selanjutnya menjadi "On" Jika settingan berhasil. Selanjutnya pastikan password YouTube tidak diketahui oleh buah hati orangtua dan usahakan buah hati orang tua tidak mempunyai akses untuk masuk ke kontens dewasa lain yang mampu membuat settingan berubah.

\section{Cara Memblokir kontens dewasa pada Google}

Sama halnya dengan youtube, pada Google Search ada pengaturan penelusuran "SafeSearch Filter" atau "Filter Telusur Aman". Langkah dalam mengaktifkan adalah dengan

Masuk/login ke Google dan klik [pengaturan] selanjutnya pilih [pengaturan Penelusuran] (lihat gambar dibawah).

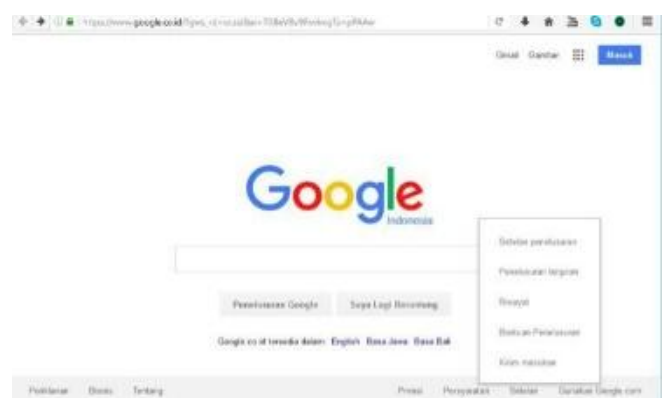

Gambar 3. Tampilan Laman Google
Selanjutnya saudara buka layar "Setelan Penelusuran" seperti gambar dibawah ini. Pada pilihan "Filter TelurusAman" atau "SafeSearch Filters" klik [Aktifkan TelusurAman]. selanjutnya pilih [Gembok TelusurAman] agar setingan terkunci.

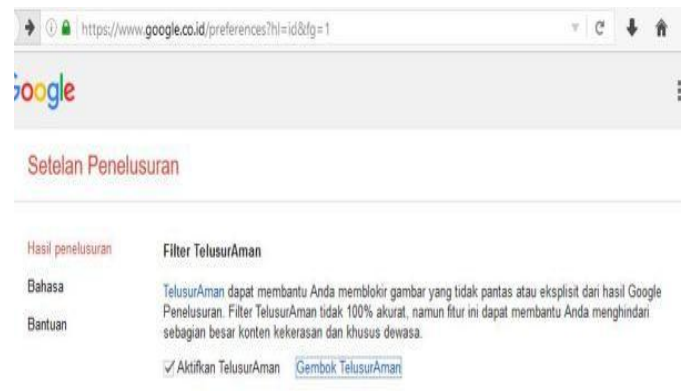

Gambar 4. Tampilan menu setelan pada Google

selanjutnya saudara akan mendapatkan proses aktivasi telusur aman/safe searching seperti pada gambar di bawah ini. Klik tombol [Gembok Telusur Aman] dan tunggu sampai proses selesai $100 \%$ (lihat gambar dibawah selanjutnya).

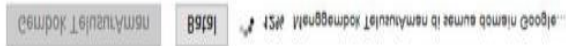

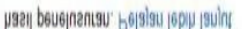

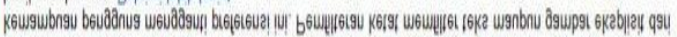 Wอuda

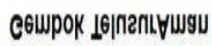

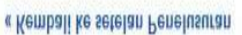

\section{Gambar 5. Tampilan Laman Google aktifasi}

Selanjutya apabila langkah ini sukses, layar penelusuran dalam Google akan ada teks "SafeSearch is Locked" dan ada 3 bola berwarna kuning, merah dan biru yang menyatakan telah aktifnya SafeSearch. (lihat gambar dibawah selanjutnya) 


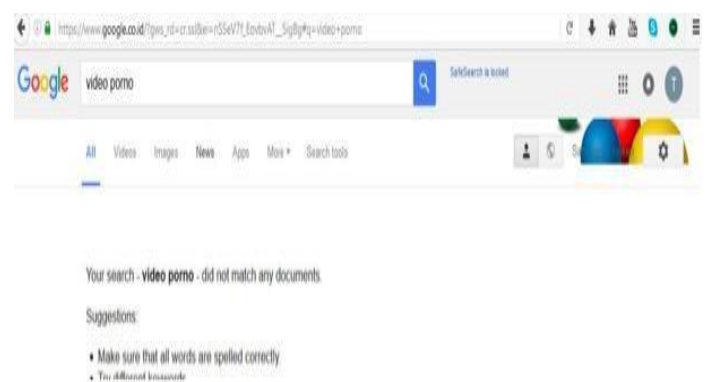

Gambar 6. Tampilan menu safeseaarch pada Google

Pengaktifan pencarian aman harusnya dilakukan pada tiap peramban/aplikasi. Akses penggunaan harus dibatasi supaya anak tidak membuat peramban baru.

\section{SIMPULAN}

\section{Simpulan}

Gadget memang sangat sulit jika dilepaskan dalam kehipunan sekarang ini karena gadget mempunyai dampak positif dan negatif. Peran serta menjadi penentu utama dalam perkembangan dini anak-anak terutama pengaruhnya terhadap penggunaan gadget

\section{Saran}

a. anak-anak bisa menggunakan gadget sebagai mestinya dan sewajarnya.

b. Peran serta orang tua sangat besar dalam penggunaan gadget sehingga pilih aplikasi-aplikasi yang sekiranya membawa manfaat buat anak-anak.

c. Tempatkan gadget di umum sehingga anak-anak mudah dipantau penggunaanya dalam pemakaian gadget.

d. Perlunya ada durasi waktu terhadap pengguanaan gadget pada anak-anak.

e. Bantu anak-anak agar terbisasa lepas dari gadget sehingga proses belajar anaanak terhadap lingkungan sekitar tidak terganggu terhadap gadget

\section{DAFTAR PUSTAKA}

Hadiwidjodjo. 2014. Dampak Positif Penggunaan Gadget Bagi Anak,

Kusuma. Yuliandi dan D. Ardhy Artanto. 2011. Internet untuk Anak Tercinta. Jakarta: PT Gramedia Widiasarana Indonesia.

Nurmalasari dan Devi Wulandari. 2018. Pengaruh Penggunaan Gadget Terhadap Tingkat Prestasi Siswa Smpn Satu Atap Pakisjaya Karawang. Jurnalilmu Pengetahuan Dan Teknologi Komputer. VOL. 3. NO. 2FEBRUARI2018E-ISSN: 2527-4864

Puji Asmaul Chusna. 2017. Pengaruh Media Gadget Pada Perkembangan Karakter Anak. Dinamika Penelitian: Media Komunikasi Sosial Keagamaan

Ramdhan Witarsa, Rina Sri Mulyani Hadi, Nurhananik, Neneng Rini Haerani. 2018. Pengaruh Penggunaan Gadget Terhadap Kemampuan Interaksi Sosial Siswa Sekolah Dasar. PEDAGOGIK Vol. VI, No. 1, Februari 2018. 9-20

Syahra, R. (2006). Informatika Sosial Peluang dan Tantangan. LIPI. Bandung.

UU RI Sisdiknas Nomor 20 tahun 2003 Tentang Sistem Pendidikan nasional. 